\title{
Surface roughness obtained at stamping of bearing cages
}

\author{
Marius Ionuț Rîpanu ${ }^{1}$, Gheorghe Nagîț $^{1}$, Laurențiu Slătineanu ${ }^{1}$, Oana Dodun ${ }^{1, *}$ and Andrei \\ Marius Mihalache ${ }^{1}$ \\ 1 “Gheorghe Asachi” Technical University of Iași, Department of Machine Manufacturing \\ Technology, Blvd. D. Mangeron, 59A, Iaşi, Romania
}

\begin{abstract}
Stamping of the bearing cages ensures a high enough productivity and consistency with the requirements of a large series manufacture. The roughness of stamped surfaces is one of the parameters for assessing the quality of the cages, which in its turn determines the behaviour in service of the bearings. A large number of input factors corresponding to the stamping process exert influence on roughness parameters. An experimental research has been conceived and developed to assess the influence exerted by the thickness of the blank and the clearance between the active elements of the die on the value of the surface roughness parameter $R a$. The mathematical processing of experimental results allowed the identification of empirical mathematical models and graphical representations were designed to offer additional information concerning the influence of the two input factors in the stamping process on a quality parameter of the bearing cage.
\end{abstract}

\section{Introduction}

The bearings are complex machine elements used to support parts found in rotation or oscillation movements (shafts, gears, belt pulleys, cable rollers, rotary tables etc.). Essentially, a bearing includes an outer ring, an inner ring, rolling elements and bearing cage. The main function of the bearing cage is to avoid the direct contact between the rolling elements. In the case of roller bearings, the bearing cage ensures also the guiding of the rolls, while in the bearings with separable rings, the bearing cage retains the rolling elements so that they could not fall, when mounting or dismounting the bearing $[1,2]$.

The quality of the bearing cage could be connected with its functions; due to the dynamic solicitations, the materials for bearing cages should be characterized by a good mechanical strength. A low value of the friction coefficient could increase the efficiency of using bearing cages. On the bearing cage service behaviour, the accuracy, the surface roughness, the properties of the surface layer and the state of edges also exert influence.

Due to high quality requests specific to the bearings and due to their various fields of use, certain materials and manufacturing techniques were gradually selected for obtaining bearing cages. Thus, for the bearing of universal use and of small dimensions, the bearing

\footnotetext{
${ }^{*}$ Corresponding author: oanad@tcm.tuiasi.ro
} 
cages are achieved from drawn sheets of carbon steel, by successive processes of cutting, punching and drilling. If the bearing cage includes two components, as the case of radial ball bearings is, the assembling is achieved by clinch.

In the case of stamped bearing cages, the main factors able to affect the bearing accuracy are the dimensions and the configuration of the bearing, inclusively the blank thickness, the type and the properties of bearing cage material, the state of the cutting tool edges, inclusively the size and the uniformity of their wear, the clearance between the tool components involved in the stamping process, the sheet flatness, the type and the constructive solution of the stamp, the way of clamping the blank, of limiting the blank feed movement, the existence of a lateral pressure exerted on the blank, the type and the state of the stamping machine etc.

The state of the cut surface state is affected by the same factors able to influence the stamping accuracy.

Over the years, the researchers developed investigations concerning the influence of distinct factors on the stamping accuracy and on the state of the cut surfaces. Usually, the cut surfaces show two distinct zones, one smooth along about $1 / 3$ of the blank thickness and the other characterized by rupture aspects, along $2 / 3$ of the blank thickness. Due to the presence of clearance between stamping tool components, the resulted surfaces could present a certain slope.

Saez de Argandoña et al. proved the negative influence of the clearance size between the stamp active components on the geometry of the part, on the cut surface state and on the bur size [3]. They consider that there is an optimal value of the clearance between the surfaces of the stamp active components, when the negative results are minimum.

If the clearance have a low size, one could show that the surface roughness parameter $R a$ could have value under $3.2 \mu \mathrm{m}$ and even under $1.6 \mu \mathrm{m}$, the burs size does not exceed $0.01 \mathrm{~mm}$, the thickness of the hardened surface layer is lower than $0.3 \mathrm{~mm}$ and the hardness could be with $40 \mathrm{pp}-80 \%$ higher than the hardness of the blank base material $[4,5]$. In order to obtain a low surface roughness, higher cutting speed and lower blank thickness could be used, when it is possible [6,7].

The main objective of the research presented in this paper was to estimate the optimal values of the stamping process input parameters, to obtain a surfaces of good quality.

\section{Process of cutting the windows in the bearing cages}

Some considerations concerning the obtaining of cages of radial-oscillating bearings with coil rolls will be subsequently formulated. The technological process of manufacturing bearing cages includes operation of cutting, drawing,

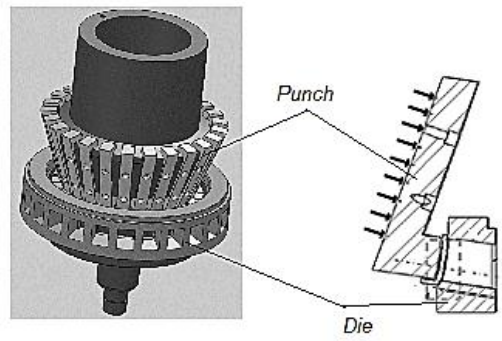

Fig. 1. Stamp components acting on the blank material during the process of cutting the windows in bearing cage and the way in which the punch detaches the window zone [2]. cutting and calibration of the bottom, perforation of the windows, turning of the external surface, deburring in drums, phosphating, quality control etc.

Generally, the cutting process involved in obtaining the cage windows needs a movement achieved by the punches along a direction perpendicular to the generatrix of the internal conical surface 
of the cage (fig. 1). This movement is achieved under the action of the conical surface of the active zone of a central mandrel. As a result of force exerted by the punches sharpened edges, the blank material is pressed up to the moment when the first cracks appears; practically, a shearing process is gradually initiated. The propagation of the cracks and the continuation of the work movement achieved by punches, in a subsequent sequence, determines the removal of the blank material corresponding to windows. Since a certain clearance exists between the surfaces of active components of the stamping tool, a burr attached to the cage is also generated. As above mentioned, the height of the burr is dependent on the size of some process input factors.

The blank material has a not uniform movement under the action of the punch; on the other hand, the tool edge is not a simple smooth curve; at a micro level, certain irregularities of the tool edges could be observed. As a consequence, the cut surface will present some asperities which constitute the surface roughness.

Generally, the surface roughness includes the periodical and not periodical asperities characterized by a ratio between the wave length lower than 50 (sometimes, 40 is the value taken into consideration for this delimitation). There are many parameters applied to evaluate the surface roughness; one of the most used such parameters is the arithmetic mean deviation of the profile, symbolized by $R a$.

One could consider that the main factors able to exert influence on the cut surfaces in stamping process are the clearance between stamp active components, the blank thickness, the length of the punch stroke, the cutting speed.

It is expected that if the clearance, the work stroke length and blank thickness are low, the surface roughness could be lower also.

A systemic analysis of cutting windows in bearing cages could highlight the main

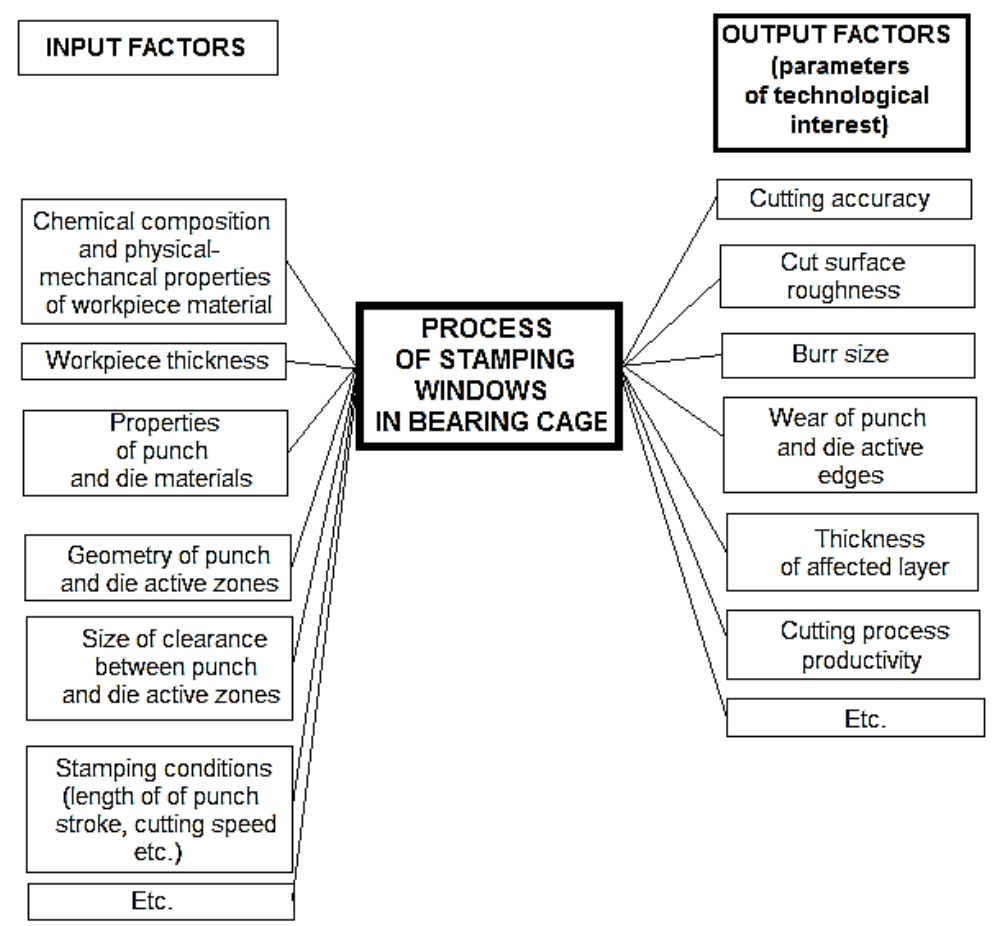

Fig. 2. Systemic analysis of factors able to affect the values of the parameters of technological interest at cutting of windows in bearing cages. 
groups of factors able to affect the sizes of the parameters of technological interest (cutting accuracy, cut surface roughness, burs size, punch wear, thickness of hardened surface layer (fig. 2). One could see that the main such groups of factors are:

1. Chemical composition and physical - mechanical properties of blank material (friction coefficient, shear resistance, hardness, yield strength, formability etc.);

2. Properties of punch and die materials;

3. Geometry of punch and die active zones;

4. Size of clearance between punch and die;

5. Length of punch work stroke and cutting speed etc.

\section{Conditions of experimental research}

An experimental research was planned and materialized in to partially test the abovementioned hypotheses concerning the factors able to affect the surface roughness at the cutting of windows in bearing cages. Metallic plates made of DD13 (1.0335, EN 10111) steel were used as test pieces.

The experimental research was developed on a hydraulic pressing machine type LVD 600 , equipped with a stamp for perforating and calibrating windows in bearing cages [1]. The values of the surface roughness parameter $R a$ were measured by means of a Form Talysurf Series 2 equipment.

Experiments using distinct values for the blank thickness $t$ and clearance $c$ between the active components of the stamp were planned and achieved. Each experiment was achieved twice. Three values for the blank thickness were taken into consideration: $t_{1}=3.5 \mathrm{~mm}, t_{2}=4$ $\mathrm{mm}$ and $t_{3}=5 \mathrm{~mm}$. As one could see in Table 1, the clearance $c$ had values between 0.11 and $0.18 \mathrm{~mm}$.

Table 1. Influence exerted by the clearance $c$ and blank thickness $t$ on the surface roughness parameter $R a$ (length of work stroke $l=6.5 \mathrm{~mm}$ ).

\begin{tabular}{|c|c|c|c|c|}
\hline \multirow{2}{*}{$\begin{array}{c}\text { Number } \\
\text { of experiments } \\
\text { set }\end{array}$} & Clearance, $\boldsymbol{c}, \mathbf{m m}$ & \multicolumn{3}{|c|}{$\begin{array}{c}\text { Surface roughness parameter } \boldsymbol{R a}(\boldsymbol{\mu m}), \\
\text { for blank thickness, } \boldsymbol{t} \text { mm }\end{array}$} \\
\cline { 3 - 5 } & & $\mathbf{3 . 5}$ & $\mathbf{4 . 0}$ & $\mathbf{5 . 0}$ \\
\hline 1 & 0.11 & 0,43 & 0,47 & 0,47 \\
\hline 2 & 0.13 & 0,50 & 0,56 & 0,62 \\
\hline 3 & 0.14 & 0,57 & 0,63 & 0,68 \\
\hline 4 & 0.15 & 0,60 & 0,67 & 0,73 \\
\hline 5 & 0.16 & 0,62 & 0,70 & 0,74 \\
\hline 6 & 0.17 & 0,63 & 0,70 & 0,76 \\
\hline 7 & 0.18 & 0,70 & 0,77 & 0,81 \\
\hline
\end{tabular}

The measured values of the surface roughness parameter $R a$ were inscribed in Table 1 . The experimental results were mathematically processed by means of a specialized software based on the use of the method of least squares [9].

The software allows the selection of the most adequate empirical model by means of the Gauss's criterion; these criterion takes into consideration the sum of least squares corresponding to the differences between measured values and values allocated by considering a certain mathematical model, for the same experimental points. The lower is the value of the Gauss's criterion, the more adequate is a certain mathematical empirical 


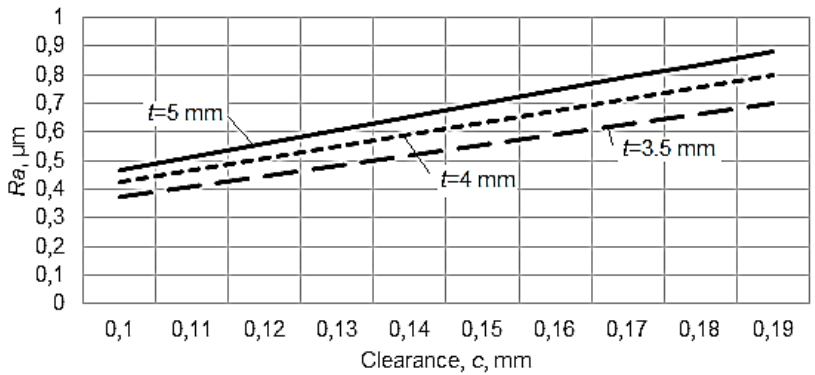

Fig. 3. Influence exerted by the clearance on the surface roughness parameter at cutting the windows in bearing cages (work stroke length $l=6.5 \mathrm{~mm}$ ).

model. The empirical models proposed are the polynomial of first and second degree, the power function, the exponential function, the hyperbolic function.

By mathematical processing of the experimental results, among the five possible empirical functions, the following was found as the most adequate to the experimental results:

$$
R a=-1.848+12.320 c-28.330 c^{2}+0.549 t-0.0561 t^{2}
$$

the value of the Gauss's criterion being $S_{G}=0.0003344253$. Since in machine building the power type function are used frequently, one established also such a function:

$$
R a=2.176 c^{0.985} t^{0.456}
$$

in this case, the Gauss's criterion having the value $S_{G}=0.0006295096$.

On the base of the mathematical empirical model constituted by the relation (2), the graphical representations from figures 3, 4 and 5 were elaborated.

The analysis of the mathematical empirical model (2) and of the graphical representations allowed the formulation of some conclusions. Thus, one notices that the clearance $c$ exert an influence higher than the blank thickness $t$, since the value of the exponent attached to $c$ in the mathematical empirical model (2) is higher than the value of the exponent attached to the blank thickness $t(0.985>0.456)$. The increase of the both factors, clearance $c$ and blank thickness $t$ determines an increase of the surface roughness parameter $R a$.

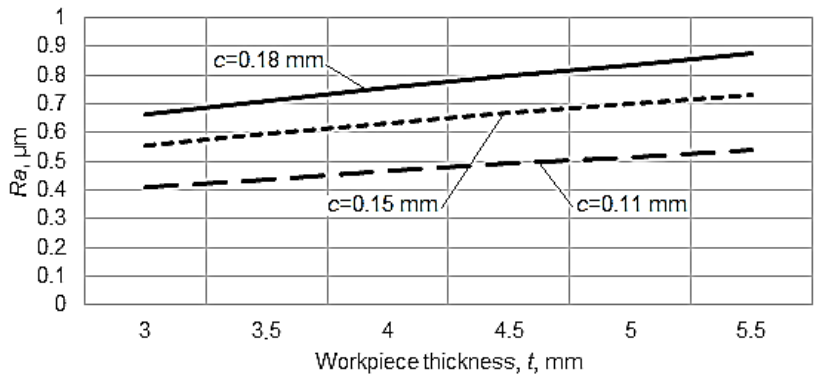

Fig. 4. Influence of the blank thickness $t$ on the value of the surface roughness parameter Ra at cutting windows in bearing cages (stroke length $l=6.5 \mathrm{~mm}$ ). 


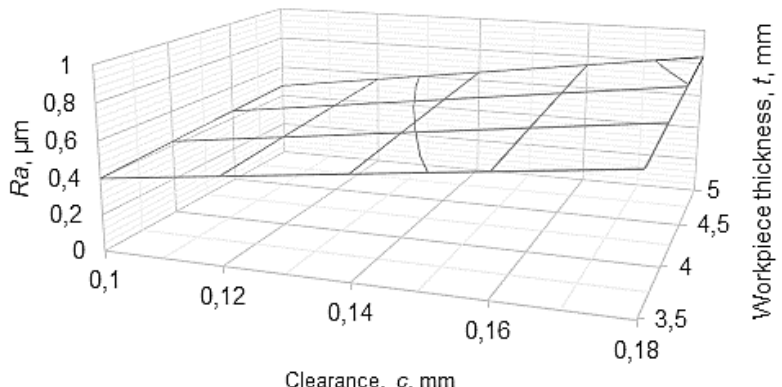

Fig. 5. Influence of clearance $j$ and blank thickness $g$ and on the value of the surface roughness parameter $R a$ at cutting windows in bearing cages (work stroke length $\mathrm{l}=6.5 \mathrm{~mm}$ ).

\section{Conclusions}

One of the technological solutions applied to obtain windows in bearing cages is the application of a stamping process. The main factors able to affect the values of the surface roughness parameter $R a$ of the cut surfaces obtained by stamping process are the clearance between the active components of the stamp, the blank thickness and the cutting speed. In order to obtain a mathematical empirical model able to highlight the influence exerted by the clearance and the blank thickness on the value of the surface roughness parameter $R a$, a theoretical analysis of the stamping process and an experimental research were planned and achieved. The experimental results were mathematically processed by means of a software based on the method of last squares. A mathematical empirical model power type was determined. The graphical representations elaborated on the base of the mathematical empirical model could be used to choose the right value of the clearance for a required value of the surface roughness. In the future, there is the intention to experimentally validate the mathematical empirical model and to extend the experimental research, to include the cutting speed in the empirical mathematical models.

\section{References}

1. M.I. Rîpanu, Theoretical and experimental researches regarding the quality and precision of stamped bearings cages, Doctoral thesis ("Gheorghe Asachi" Technical University of Iași, 2014)

2. FAG Rolling Bearings, Ball bearings. Roller bearings. Housings. Accessories, (Catalogue WL 41 520-3 EA), (1999)

3. E. Sáenz de Argandoña, A. Azoturia, C. García, N. Arana, A. Aguirre, P. Filaria, Robot. CIM-Int. Manuf. 24, 773-779 (2008)

4. P. K. Rai, A. Mohammad, H. Z. Jafri, Int. J. of Eng. Res. and Appl. 3, 511-515 (2013)

5. G. Angara, G. Imbroglio, et al, J. Clean. Prod., 29, 255-268 (2012)

6. A. Florentino, E. Curette, A. Athanasios, L. Mazzini, C. Giardini, Int. J. Mater. Form., 2, 805 (2009)

7. P.V.P. Macondo's, A.M. Eton, P.A.C.Beltrão, P.C. Borges, J. Mater. Process. Tech. 206, 184-193 (2008)

8. P. Sartkulvanich, B. Kroenauer, R. Grolle, A. T. Alta, CIRP Ann.-Manuf. Tech. 59, 279-282 (2010)

9. G. Crețu, Fundamentals of experimental research. Laboratory handbook ("Gheorghe Asachi” Technical University of Iași, 1992) 